\title{
A Defensive Driving Course for the Language Lab
}

$\mathbf{I}$ $\mathrm{n}$ our discussions and publications about language laboratories, we-in foreign and second language education-often overlook the daily realities faced by those who are the frontline players in the language teaching and learning arena, namely, classroom teachers and their students. One way we can overlook the learning arena is by posing and examining questions such as the following which, though important in themselves, are often not directly relevant: What is the best type of lab? How do the features of the various brands compare? What kind of lab furniture is most appropriate? What is the best layout? What kind of cataloguing system should be instituted? Were we to use the world of automobiles as analogy, we would be asking: What kind of car is best? What new features should be included in car design? What is the optimum use of interior space? Should form follow function or function follow form?

For those of us coming from a more academic stance, the questions posed and discussed might include: Should one use a language lab at all? What are the best applications of the lab across the curriculum? What is the relative value of different kinds of language lab activities? Continuing with our automobile analogy, academic questions might be: What are the merits of owning an automobile? Should one take one's automobile to work? What are the advantages of automobile ownership over public transportation?

Occasionally, a few among us ask more downto-earth questions like: Where can one find good lab materials? How can teachers make their own lab tapes? Or, in auto terms: Where can one find good snowtires? How can one manage one's own oil change?
All of the issues posed by the above-mentioned questions are important. What is missing, however, is a fundamental issue applicable both to the world of language education and the world of automobiles. In the world of automobiles, that fundamental issue is learning to drive; more importantly-as any driving instructor is quick to point out-learning to drive defensively. Driving an automobile defensively can be defined as learning to prepare for and managing the avoidance of frustrating and potentially disastrous situations. Analogously, in the world of language education, learning to use and manage the language lab is important but not as important as managing and using the lab defensively.

For many language teachers, experiences with language labs mirror those of motorists thrown into rush-hour traffic with only rudimentary information about where brake and gas pedals are located. Likewise, with only rudimentary instructions on lab use and management, most language teachers find the laboratory a frustrating, nerve-wracking experience which colors all their subsequent thoughts on the subject. Worse still, many teachers first encountered the "lab experience" from the perspective of having themselves been language students-a perspective characterized by an attitude conveyed by the following exchange: Student A: "Hey, what did you do in the language lab?" Student B: "Sixty minutes."

Given the fact that many teachers have only rudimentary information about language labs and given the fact that for many teachers-and many students-using the laboratory is often frustrating, non-productive, and nerve-wracking, it is the goal of this article to serve as a guide on how to use and manage language lab technology defensively. Using the language lab defensively 
helps teachers teach and students learn languages effectively. In the hands of a knowledgeable, confident teacher, the language lab serves in preparing students for language learning and linguistically equips them to avoid frustrating and potentially disastrous communication errors, blunders, and breakdowns in target language manipulation.

\section{Knock, Knock. Who's there? A Dinosaur.}

A guide must have a beginning, and the logical place to begin a lab-use-and-management guide is by examining the popularly held notion that language labs are somehow the prime example of a "failed" technology. While this notion seems most evident to English as a Second Language (ESL) teachers in North America, it is a viewpoint held by many second and foreign language teachers as well. As far as notions go, it is a comfortable one, since it allows teachers to rationalize their gut feeling of dislike for the lab-a dislike often justifiably based on rudimentary understanding of lab technology or on many frustrated attempts at trying to make successful use of it.

The rationalization goes something like this: Language labs were a product of the behaviorist approach to language teaching so popular in the 1950's and 60's-an approach which has since fallen into disrepute. Furthermore, all that really can be done in labs is drilling: three- and fourphase exercises in which students repeat endless series of meaningless, uncontextualized utterances-activities which also have been shown to be of little use in learning language. Therefore, any modern and valid teaching activity is as easily-if not more easily-done better in the classroom with a tape recorder than with a language lab. Besides, the complicated equipment never worked anyway. For these and other reasons, what reasonable person wouldn't think of language labs as technological dinosaurs?

\section{Dinosaurs by Any Other Name Still Flourish}

Reassuring and comfortable as old notions can be, reality often has a way of upsetting accepted dogmas and rationalizations. Twenty years after their supposed peak and impending demise, the dinosaurs called language laboratories are still alive and flourishing. Not only are they alive, but their manufacturers are having no trouble selling them; in fact, language labs are "doing very well, thank you." (For a listing of laboratory system manufacturers, please see the J.E.T.T. Fact Finder at the end of this article.)

Language labs in the Age of Information are no longer the monstrous, complicated, and expensive beasts of days gone by. For the most part, today's labs are fairly reliable, relatively inexpensive, and not inordinately complicated to operate. Moreover, today's labs adhere to a more "open" concept. The nearly sealed isolation cubicles of yesteryear have given way to open, multi-purpose labs with only a minimum of separation between students. Gone, too, are the large, bulky, and cumbersome headsets. It appears that not only are labs becoming very streamlined, very high-tech, and very sleek, but they also seem to be here to stay.

If language labs are evolving into high-tech hardware, what about laboratory exercises, materials, and activities? Even with modern lab technology in the labs, aren't students still lockstepping to the beat of the Skinnerian drummer in the carrels?

Even in the heyday of the audio-lingual (behavioristic) method of language teaching and learning, teachers committed to using the lab as learning tool shared an open secret: All of them knew that lab exercises, materials, and activities did not have to be Skinnerian, meaningless, and dull. Since the heyday of behaviorism, committed educators and media experts have been evolving and transforming the pedagogy of language labs. A number of noteworthy books on useful and effective exercises, materials, activities, and applications have been published over the years, and there have been and are a number of educational conferences dedicated to the advancement of laboratory use. (For a listing of conferences and recent books on language laboratories, please see the J.E.T.T. Fact Finder at the end of this article.) 


\section{Encounters Not Always of the Perfect Kind}

This is not to say teachers today will only encounter language labs which are modern, trouble-free, and amply stocked with lab exercises and applications incorporating all the advances in language lab pedagogy developed over the last 20 years.

Unfortunately, all too many teachers will have to get by a bit longer with old, rusty dinosaur labs and manage to find ways to minimize the effects of equipment failure and antiquated design. Time-consuming and difficult as an out-dated lab can be, teachers should take the time to inform themselves about the latest lab technology available on the market. By being knowledgeable and aware, teachers can exert influence so that lab equipment can be replaced and lab space redesigned. However, as many of us in Academe know, it is a troublesome feature of most administrations that usage must go up before new monies are allocated.

If we apply the troublesome administrative feature of "usage determines allocation of money" to language labs, what exactly is being used and for what will new monies need to be allocated?

The term "language lab" can confusingly refer to many different things. It can refer to the equipment itself; to the full setting -including lab furniture-in which the equipment is installed; to the room in which the installation is placed; and finally, to the administrative unit that operates the installation. Although teachers in general have little direct control over a number of the elements that comprise a language lab, their successful use of the facility requires at the very least a layman's knowledge and understanding of all its elements. Although teachers will most likely encounter numerous brands and models of lab equipment in the course of their careers, in evaluating a specific type-in terms of what it can do and what it costs-it is necessary to understand something about basic lab components in general.

\section{Language Lab Equipment}

Portable or Built-in. Today, language lab equipment falls into two large and very general categories: There are the so-called "portable" labs and the so-called "built-in" or wired labs. A manufacturer may offer the same model lab in either version.

Because an institution is unable to dedicate space to the establishment of a permanent language lab, its administration may allocate funds for a portable lab. The rationale behind such a lab is that it can be brought into an existing classroom; it eliminates both the need to move students to another location and the need to find space for installation of a permanent lab.

Generally speaking, portable labs have fewer features than the larger, built-in labs; most, however, do offer all the standard features. Besides their portability, these labs are usually quick and easy to set up. The absence of the familiar lab carrel eliminates the psychological benefits of isolation so common in the traditional built-in lab. However, the portable lab headsets provide adequate sound isolation for most lab activities and prevent students from disturbing one another.

With access to a portable lab, students lose the benefits of "going to another place" to do their lab work-an activity which in itself can often be positively exploited even with a portable lab. The collection and distribution of the lab equipment in a portable lab situation can provide the "needed" breaks prior to and after a lab session.

Some portable labs are defined as "wireless." Typically, in such labs, student headsets have a radio receiver/transmitter which links them to the lab system. There is probably no lab that is quicker to set up than a wireless: Just hand out the headsets and turn the system ON.

Ease of set-up notwithstanding, wireless portable labs have some disadvantages. Often wireless labs do not offer the traditional array of standard features; most notably, students may not be able to record their voices for playback. The headsets of a wireless lab with their receiver/ transmitters tend to be heavier and more bulky than their standard counterparts, although this situation is improving. Perhaps, the gravest criticism of wireless labs is the fact that greater interference is possible in open radio waves. 
However, one must bear in mind that there are elements in even a top-of-the-line built-in laboratory that can cause radio interference as well.

For many administrations, one of the most attractive features of the portable lab is its cost. Because such labs often have fewer features, they tend to be less expensive than their manyfeatured, built-in cousins. Moreover, portable labs can be "permanently" installed once space becomes available.

As the technology of portable language labs improves, so, too, the technology of wired or built-in laboratories. Gone are the thick bundles of wire, one wire for each function at each student position. Nowadays, through multiplexing and digital technology, a single cable can snake its way through the entire lab, connecting all the student positions. Gone, too, are the large recorders which took up most of the writing surface in the student carrels.

While today's language laboratories do not bear much physical or technical resemblance to the labs of the 50's and 60's, they nevertheless share the same common set of basic functions and abilities which allow them to serve as specific, special, and rather remarkable learning tools.

Language Lab Equipment: Headsets. A language lab headset is special in that it has a microphone attached to it; the sound from the microphone is amplified and played back through the earphones. This is one of the fundamental features which make language labs a special tool. Such "hearing" can be invaluable in pronunciation practice and cannot be easily duplicated at home or in class with ordinary tape recorders. Language lab headsets offer students in even a modest lab an opportunity to "hear themselves as others hear them."

Language Lab Equipment: Recorders. A standard language lab provides each student with a personal recording/playback device. In cassette labs, each student position includes a personal cassette recorder. In recent years, the cassette recorders used in labs have been engineered to be quite rugged and reliable. They do require routine maintenance, however. Most notably, the tape heads, capstans, and pinch rollers must be cleaned regularly. A recorder cleaning schedule depends, in part, on the cassette tapes used in the machine. As a rule of thumb, it is more important to use cassettes having very well-engineered and rugged moving parts (called the "tape transport") than those with the highest sound quality. The three-for-99-cents variety of cassette tapes are attractive in price but not in performance: their tape oxides clog tape recorder heads and pinch rollers; their overall sound quality is inadequate over the long run. Although teachers at many institutions can leave considerations of tape and recorders to lab personnel or technicians, there is no substitute for personal knowledge about such matters.

Before the advent of cassettes, language labs used reel-to-reel tape recorders, some of which are still operational at institutions throughout the world. The latest technology applied to language labs involves digitally storing both the lesson program and students' voices on computer media. In the long run, this will probably be much more flexible and reliable than cassette recording. Nonetheless, most installations today remain cassette labs; therefore, the remainder of the current discussion will revolve around "listeningspeaking-recording" cassette labs.

Novices-and even long-time users of the lab-are often confused because language lab cassette recorders do not operate in exactly the same fashion as regular off-the-shelf consumer tape recorders. The head configuration of lab recorders is such that two electronic tracks are simultaneously recorded on the cassette tape: the so-called "master" or teacher track and the student track. In addition, lab machines are available in "halftrack" configuration or "quarter-track" configuration.

As the name implies, the student track records whatever comes through the microphone on the lab headset. The master or teacher track is not affected by recordings made by the student; the master track usually contains the exercises found on a tape program which accompanies many publisher textbooks or exercises devised by teachers.

Adding to the confusion is the fact that tapes produced in a language lab with a so-called "half- 
track" head configuration on its recorders are not compatible with standard, off-the-shelf cassette recorders when it comes to recordings on the student track. Teachers need a matching halftrack machine if they want to take home the student tapes to, for example, correct an exam. Teachers who prepare tapes to be placed into student machines must take care to record the lesson on Side One of the tape only (Side Two is in effect the student track and will be erased by the student's voice). Language lab cassette recorders with the so-called "quarter track" head configuration are compatible with standard, offthe-shelf machines; cassettes recorded in machines with quarter-track head configuration can be recorded on "both sides" or in both directions, and the student track can be heard.

Student lab machines generally have the normal tape recorder controls: Rewind, Stop, Play, Record, and Fast Forward. These are often given flashy names, like "Speak" for record or "Wind" for fast forward; such labels can confuse more than help the students. Most lab machines have an extra function: Recap. Whereas Rewind spools the tape backwards very quickly, Recap only goes back a few seconds, or sometimes to the previous pause in the audio signal. Recap is useful for listening to the same word or phrase several times in succession. Additionally, most machines also have a Teacher Call button with which students can signal for assistance from the teacher at the console. An indicator flashes on the console and may remain illuminated until that student is selected.

Students usually have two volume controls, one for the master track and one for the student track. They can thus adjust the relative volumes of the lesson and their own voice. Student volume often only works on playback, but if it should always be operational, turning it down can reduce interference from other, louder students. The Tape Counter is an important feature with which students should become familiar. It allows them to note the location of important elements in the program so that they can return easily for more detailed work. Students should also be shown how to use the Counter Reset Button. Regular tape counters are not extremely accurate across different machines. Some labs have "real-time" counters which count the passage of tape in minutes and seconds. These tend to be accurate, even on different machines.

\section{Language Lab Equipment: Control} Console. In addition to the individual student machines, the standard language lab has a control console which enables teachers to supervise and control the entire lab. Teachers cannot rely on lab personnel to operate the lab for them. If they are to get the full benefit of the lab, they must learn the basic control functions of the lab and operate it directly. There is no harm, of course, in leaving more sophisticated operations, such as lab setup, to the technicians-provided there are technicians or lab personnel to do it.

There are two basic modes of operation in the lab: The lab can be under teacher-control or student-control.

In theory, under teacher-control, the controls on all the student machines are inoperable from the student position; the teacher can run the entire lab directly from the console. Under studentcontrol, students can control some or all of the functions on their machines. In some labs, teachers may be able to place individual machines under teacher-control, while leaving the rest of the class to work independently or in student-control.

Regardless of the mode of operation, teachers can monitor each individual student without students being aware of it. (With some older labs, students may detect a sound change. Teachers should check on this.) Teachers may speak to one individual student or to an entire group of students. More powerful labs allow teacherswhen monitoring an individual student- - to see the placement of all the controls on the individual's machine. Such a feature can be very helpful in determining why a student may be having difficulty.

The Speak-to-Group function can be a source of great confusion. In many labs, it is not the same as Source-Microphone. In such a case, what is said on Speak-to-Group would not be recorded on the student tapes. It has happened that a teacher has "recorded" a dictation on all the student tapes by reading it aloud, only to find that the master track on all student machines is 
still blank. When the lab is in student-control mode, Speak-to-Group or Speak-to-Individual-Student (Intercom) will stop the student machine(s). In some labs, the original operation of the machine(s) will resume as soon as the function is terminated. In others, the student machine(s) remain stopped. In such a case, if the lab allows, the teacher should take control, restore the original function, then release control again. Or, at least, remind the student(s) to resume operation manually.

At a minimum, teacher-control permits the stopping of all the student machines and rewinding them. In addition, it is the mode whereby the master lesson is broadcast to all the student positions. Typically, accompanying the console, is at least one source playback unit. Often, there is more than one, or the console may have auxiliary input plugs which can take others. The teacher's microphone is also a possible source.

It is important, when beginning to broadcast, to check the Source-Select switch to make sure the right source is going out to the students. Many lab consoles also have an indicator for the sound intensity of output (Level Indicator) and a Level Control for the output. Teachers should always turn the Level Control off before beginning the playback. They can then bring it up slowly as they watch the Level Indicator. Serious damage can be done to the students' ears by a high volume blast! (For the same reason, teachers should keep their own headset volumes low as they monitor students.) Once the proper sound level has been set at the console end, teachers can be fairly certain that any complaints about sound level are to be adjusted at the students' end, with their own individual volume controls. Sometimes, lab consoles have a Listen-Only function, which allows a lesson to be broadcast to the students without having to be recorded on their cassettes.

What has been described above constitutes the essential features of a full service "ListeningSpeaking-Recording" language lab. These functions are sufficient for the full utilization of the most important teaching/learning possibilities offered by language labs. A system offering fewer features does not prevent teachers from deriving advantage from the lab; it simply curtails the range of activities that can be done.

Lab Equipment: Extra Features. More expensive language laboratories often exhibit some interesting, though not always universally useful, additional features.

It might be possible to separate the lab into distinct "groups." Each group is controlled separately, and may even be listening to separate programs. Though this sounds attractive in principle, the logistics of managing two or three separate activities simultaneously is beyond what most teachers feel comfortable with. In large lab installations, the Group feature is often used as a mechanism for accommodating two different classes in the lab at the same time. Often there are dual consoles. Even labs with fewer features usually allow some students to be placed on "free", placing them in student-control mode and isolating them from the group. Such a feature is a useful way to let slower students continue to work on one project, while the faster students move on to the next.

Some of the fanciest labs offer a computer memory which can keep track of student calls to the teacher. Teachers who are actively monitoring their class probably would not need this feature. If so many students are pressing the Teacher-Call button that one cannot keep track, then something is wrong and Speak-to-Group might be the appropriate avenue. When students press Teacher-Call, they want immediate attention. Calling back five minutes later is not always useful; it can disturb the student, who will no longer remember why the button was pressed in the first place.

Many of the more sophisticated labs have a "High-Speed-Transfer" feature which permits high-speed duplication at four times normal copy speed. The rationale is that teachers can then dispense with the lock-step broadcast phase and allow students to immediately begin individual work. The drawback is that students miss the global overview of the material they get from the lockstep phase. Many students will get bogged down at the beginning of the lesson and never proceed to the end. The session also loses the natural breaks that are introduced by the switch from lock-step operation to student control. 
Two of the often touted abilities of some labs are "Student-Pairing"-setting up sub-groups who can communicate with each other-and "Student-as-Source" which permits one student position to become the source for all the others. If these features are present, it can be useful to explore possible applications, but their absence will not seriously cripple the lab.

Some of the truly advanced systems allow teachers to automatically insert pauses into the program at pre-determined points as well as control the length of these pauses. This feature pre-supposes the use of the classic genre of lab exercises of the stimulus-response type and may not be that useful with more experimental types of materials. It can also easily be accomplished through dubbing from one tape recorder to another, while using the pause button on the source machine.

Another highly advanced feature of top-of-theline labs provides multiple-choice response keys to each student position, allowing students to register a (written?) response to questions posed. These labs usually have a Response-Analyzer which generates complicated statistics on class performance. The inherent limitations of multiple-choice tests or exercises affect the utility of this system for language learning applications. Nevertheless, for teachers who want and need statistical data such as the standard deviation, for example, such a Response-Analyzer will work out the statistics on class performance for them.

Since the arrival of the microcomputer revolution in the early 1980's, some lab manufacturers have found it trendy to replace the traditional control console with a computer screen. Computer controlled labs are great, so long as the role of the computer is to facilitate operations, and it does so in an out-of-sight manner. Frivolous information only complicates operations. One lab of a few years ago had a constant display on the computer screen of the "Direction of Information Flow." How many teachers would not know that when they are talking to the students, the direction of information flow is Teacher to Student?

Many of these extra features impress language lab salesmen far more than they impress teachers, who have found that successful exploitation of the language lab does not necessarily depend on the power or subtlety of the language lab equipment. Of course, there are exceptions to this general statement. The lab should offer all the basic functions described earlier. Labs that do not offer all of the basic features can still be of use, but the range of possibilities becomes seriously limited. An aging lab, on the other hand, does not necessarily have to be replaced just because it is old and out of fashion, as long as it offers all the features required.

\section{Working or Not Working? That is the Question.}

However old and simple or modern and sophisticated the language lab equipment, it is essential that it be in working order. While the defensive practices outlined later can minimize the effect on the class of equipment malfunctions, a partially or wholly disabled lab is always disruptive. What is a teacher to do, for example, when faced with a class of 30 students and a lab with only 15 working positions? There comes a time in the life of any piece of equipment when continuous repairs and servicing need to give way to the purchase of new equipment.

\section{Knowing How Lab Equipment Works}

Teachers cannot use language labs effectively if they do not have a good understanding of how the lab equipment works. Being experienced with "labs," in general, is not enough: Every installation, even of the same brand, is slightly different and has its "quirks."

If teachers do not know how to operate the basic functions of the lab, they will not feel "in control" of the lab experience. They will end up not liking the lab. They will not use the lab to its full potential, nor will they want to experiment with new techniques and approaches. What is worse is that the feelings of the teacher towards the lab are easily communicated-both verbally and non-verbally - to the students, who may end up not liking the lab either.

The time for teachers to learn how to use a language lab is not at the beginning of the teacher's first lab session with the class. At this 
time, even experienced teachers are understandably nervous: Teachers often do not know their students very well; first impressions are still being made; teachers do not want to make mistakes and look foolish; and, students look to the teachers to help them learn how to use the lab. This being the case, teachers should set aside time-prior to the first class session-to come to the lab, be shown how to operate it, and become familiar with all the basic operations, both from the console and the student's position.

Teachers notwithstanding, it is also important that students know how to work their machines. They will quickly become angry and frustrated if things do not work properly. Some language lab installations offer orientation sessions, perhaps complete with slides and videotapes. These are, unfortunately, often only marginally useful. They tend to try to teach everything there is to know about the lab, including more advanced features which the student will not remember later when needed.

Furthermore, some teachers are keen on conducting the orientation in the target language. It is a laudable goal, but little learning is going to take place if the students do not understand. One lab-dealing with ESL students from varied backgrounds-offered printed instructions in a whole host of languages. Not only do the students all understand, but they are given a psychological boost when they see their own familiar language in print, and their learning of English does not suffer.

In the beginning, things go much better if teachers make use of their console control abilities to control virtually the entire session. Control can be released to the students only when necessary. New technical aspects of lab use should be introduced one at a time, as needed: It is often effective to begin with listening activities; at the next session, students can be introduced to recording their own voices. At a later session, perhaps, they can be shown how to record, then correct.

The following real-life lab disaster provides a useful illustration: A French class received the usual first session orientation. Since this was an advanced class, the orientation was entirely in
French. Through-out the entire term, students used the lab for listening purposes only, starting and stopping the tape as they filled in worksheets. The final examination, however, required students to listen, record an original utterance, then go back and modify their recording based on new information. It was a progressive, welldesigned oral examination, but it failed miserably. The students had no practice with the technique of recording and were not receptive to having to use it for the first time under the pressure of an exam situation. After a few minutes of chaos, the exam was cancelled. The teacher never tried to use the lab again for an oral examination. In this case, the students should have been introduced to the technique gradually.

Giving students technical training on the operation of the language lab is not enough. They need to understand why they are there and the purpose behind the various features. The importance for pronunciation practice and the fact that they can hear themselves through the headsets should be made clear. They should be told why they are being asked to record their responses, and why and how they should go back and listen to them afterwards. Students need training on what exactly they are looking for when comparing their response with the model voice. Often students do what they are told, but in a half-hearted manner because they feel it to be a useless exercise. Providing students with the rationale for what they are being asked to do will help clarify this in the teacher's mind, as well as in the minds of the students. If it is difficult to justify to others the pedagogical utility of an activity, then, perhaps, some other activity should be chosen.

\section{Lab Set-Up Options}

In most cases, the lab setting and furniture are given entities to which teachers must adapt themselves as best they can. Some labs, though they may have modern equipment, are still laid out according to the classic behaviorist model of language labs: high partitions providing almost total isolation between students. In extreme cases, teachers may not even be in the same room with the students, but may find themselves instead observing through a pane of glass from the lab control room. The opposite extreme might be a 
portable language lab, in which the setting is the ordinary classroom, and there is no special furniture at all.

Sometimes, in the course of planning a new language lab facility, teachers are asked for their opinion on the lab setup. What, then, is a good lab layout, and what is appropriate furniture for conducting teacher-centered lab sessions?

Teacher and Students in the Same Room. Obviously, teachers should be in the same room as the students. It is helpful if the teacher console is on a slightly raised platform, making it easier for teachers to see the students and vice-versa. Eye-contact is a far better means of communication than the Teacher-Call button. For the same reason, students should all be facing the teacher. Two classes should not share the same room at the same time.

Blackboard, Whiteboard or Whatever. Often teachers will need to ask students to take off their headsets so that something can be explained or discussed. There should be a writing surface, such as a blackboard or whiteboard, so that examples and illustrations can be displayed.

Ample Space Between Student Carrels. With ample room between student carrels, teachers can move easily among the class. For many activities, especially those involving written performance, the control console is not the best place from which to monitor student activity.

Roomy Student Carrels. Student work spaces should be amply large to accommodate books and a writing surface, since many of the best lab activities require writing. Each work station should be partitioned from the rest, but low, transparent plexiglas partitions are probably the best. The role of these partitions is primarily psychological rather than acoustic. Acoustic isolation is guaranteed through the use of good headsets, carpets, and sound-absorbent wall covering. It is not necessary, nor desirable, to totally isolate each student. Students should be able to participate in the group by raising their heads and backing their chairs away from the desk. Conversely, the low partitions can give them a feeling of their own, private space where others cannot hear them or disturb their practice.

\section{Language Lab Administration}

The administration of the language laboratory in many cases will likely be beyond the teacher's control. In extreme cases, the language lab might be seen as simply another piece of audiovisual equipment to which teachers are given the key when needed. Though there are probably technicians on call to ensure that the machinery functions, all other support becomes the teachers' responsibility. Free access by students outside of class is no doubt severely limited under this scheme.

The language lab becomes more readily useful if, besides being just a room with equipment, it is also a functioning administrative unit, with operators and other support staff. Such a scheme allows lab staff to prepare the lab for each class, relieving teachers of this responsibility. There might also be a well-stocked and maintained library of language lab materials and activities which teachers could use in the preparation of their lab sessions. Indeed, the director of such a facility may have the background to provide teachers with expert advice, guidance, and training in the production and use of language lab materials. Finally, such an arrangement is likely to provide accessibility to students who may wish to come to the lab for independent study.

Naturally, the latter arrangement is going to cost more than the former: the salary of at least one full-time employee and part-time student help. Those who purchase language labs must be made to realize that the equipment is not the only consideration. The former approach may appear less expensive, but, if it leads to the language lab being under-used, then it is not as cost-effective as the latter.

For the rest of this article, it will be assumed that teachers have access to a Listening-SpeakingRecording cassette lab laid out according to the conditions outlined above and staffed and maintained as a functioning administrative unit.

\section{Integrating the Lab Into the Curriculum}

The technical and administrative features discussed in the previous section are largely things to which teachers must adapt, since such 
features are outside of their control. The method of using the language lab and its integration into the rest of the students' language learning experience remain, on the other hand, something over which teachers have a direct influence.

\section{Three Models of How Teachers Use the Language Lab}

Although teachers have the responsibility of determining how the lab is integrated across the language curriculum, they do not always exercise this responsibility nor does "I make my students use the lab" mean the same to all teachers. Three different scenarios or models of "using the lab" generally cover the spectrum of how teachers "feel" about the language lab as teaching and learning tool.

\section{Model I Scenario}

In the first scenario, the method or textbook for the course is chosen without the slightest consideration for the language lab program-if any-that accompanies it. If there is a lab program, often-whereas the textbook is printed on glossy four-color pages with lots of illustrations-the accompanying lab manual is in typewriter typeface on cheap paper. Not having considered the lab manual, teachers have no way of knowing if the exercises in the lab program have any connection with what is covered in the book. (Sometimes, the lab exercises are not written by the same author!) Although the text is replete with modern communicative activities, the lab manual is filled with dreary, mechanical exercises. Without having previewed the tapes, teachers do not know if the audio quality is good or bad, if the dialogues consist of a dreary alternation between two constant voices, or what exercises are practiced by their students in the lab.

Continuing with this scenario, once the tapes arrive in the lab, teachers do not take the trouble to preview them in order to become familiar with the material on them. In class, there is no attempt to prepare the students for the lab activities, or to follow up in class on what has transpired in the lab. Teachers make no attempt to thematically link the class session and the lab session.

Students are invited, or perhaps required, to include the language lab in their studies. In this scenario, teachers traditionally engage in "parenthetical" thinking, that is, saying one thing and meaning another:..

\section{Teacher: "Outside of the class work (outside of what I consider to be part of this class) you should (must) spend one hour per week in the language lab. Your attendance (not your work there) counts for $10 \%$ of your final grade."}

This first scenario is obviously a straw man. Yet, it is, unfortunately, a pretty good description of the way in which many teachers use the lab. Is it any wonder then that the language lab is not found to contribute significantly to the language learning experience? Imagine telling students, "Go home and read a book in French." or "Watch some Spanish television." As useful as these activities might be in theory, would one automatically see the improvement just by giving the assignment?

\section{Model II Scenario}

The second scenario improves on the situation in the first scenario. Teachers, or those responsible for the textbook selection, carefully consider all aspects of a given textbook or method: Do the lab exercises reflect current pedagogical wisdom? Are they appropriate and do they contribute to what is to be covered in class. Is the theme begun in class carried into the lab? Do the activities lend themselves to fruitful follow-up work, either in class or at home? Are the activities in each unit varied, so as to offer practice in many different skill areas and so as not to bore students? Are the activities "do-able", or would even native-speakers have trouble with them? (Teachers should try the activities themselves.) Is the lab manual visually attractive and yet affordable? Are the tapes clearly audible? Do they make use of varied, professional voices, with appropriate music and sound effects? In other words, do they sound professional? For new texts, is the lab program ready yet? (Sometimes it does not arrive until well into the school year, without the possibility of preview.)

Once the text or method of instruction is 
established, teachers study each lab lesson so that they can establish a link between what is happening in class and what students are doing in the language lab. One hears instructions such as the following:

Teacher: "This week in the lab you will... After your lab, give me the written responses to the activity." "We will discuss, at our next class, the situation outlined in the listening activity that you are all to do at the lab."

\section{Model III Scenario}

In cases where teachers accompany their students to the lab, a third scenario is possible. In this scenario, teachers produce a custom program for each lab session. They use some activities available with an adopted text, but they add other material as well. A 50-minute lab session is made up of three or four varied activities, usually consisting of an introductory activity, some "heavy" work, and then a light, "cool down" activity.

Typically, in this scenario, practice begins with a comprehension activity, based on a timely and authentic radio news or weather report. Students are given a definite task, graded to their level of ability. It might be something like "Write down three of the major stories." or "Tell me if I should bring an umbrella tomorrow."

A repetition exercise follows, for vocabulary and pronunciation or, perhaps, a good set of contextualized grammar exercises are assigned.

There is a dictation-a good holistic activity which practices many skills-followed by true/false comprehension questions.

Finally, students listen to a popular (modern) song from the target culture or even a familiar advertising jingle. Their task could be to complete a "cloze" exercise, or answer some questions. Some might even sing along.

Lab sessions are all different. Though a predictable format is established, each week new and interesting materials are brought into the lab.
Each lab session is tailored to the specific group.

Furthermore, teachers have prepared students before going to the lab. Key words and concepts from the morning news broadcast have been introduced. Perhaps, photos of newsworthy individuals have been shown. Each activity is followed up in class. The comprehension questions from the morning news lead into class discussion, the story of an election win, perhaps, leading into a comparison of political systems. An information gap activity loosely tied to one of the stories is provided. Using a variety of short, different activities breaks up the tedium of a single session and gives it a fast, lively pace. Teachers do not let any one activity drag out. A mental time limit is set for each activity and is cut off at that point, finished or not. If threequarters of the class finish early, then the activity is also cut off. And, of course, if the activity is "bombing," either because students do not understand the activity, how to work the equipment for that activity, or because of equipment malfunction, the cleanest, face-saving exit is just to stop it and move right on to the next exercise. Teachers in this scenario, keep an extra "back up" activity in their folder, just for this eventuality.

The lab session alternates between "recording" phases-when the student machines move in lock-step fashion under teacher control-and "playback" phases, when students work individually on the material recorded on their individual tapes. Some may argue that it is a waste of time for students to have to passively "listenthrough" material before they can work with it. First, given the appropriate task, the recording phase does not have to be a passive period. Second, nearly all lab exercises, especially the traditional ones, were designed to be done more than once. Students need the first pass through to familiarize themselves with the content and with the nature of the task. Third, the lock-step phase gives all students an overview of the material. Working independently from the outset, students could get bogged down at the very beginning of the task and lose the big picture. It is commendable to continue practicing until perfect, but students also have to learn how to move on when they get stuck. 


\section{Journal of Educational Techniques and Technologies}

This intensive use of the language lab is clearly a lot more work for the teacher. In this scenario, the time teachers spend behind the lab console is not a time for relaxation and grading papers! The burden of coming up with new and interesting materials can be greatly lessened, however, if teachers combine their efforts and contribute to some sort of common resource library. Over time, the number of tried-and-true activities in the collection would increase and a given teacher could spend more time on selection than on creation.

It is this third, intensive-use scenario that will form the basis of discussion later in this article on how best to conduct a language lab session.

\section{Language Lab Materials-The Fundamentals}

First, however, some more thought needs to be given to what teachers should be looking for in a good language lab activity. At workshops on how to make the most of language labs, teachers usually want to know what type of exercise works best. Yet it is fruitless to launch into endless discussions about the relative merits of different types of exercises and activities: substitution, transformation, three-phase, four-phase, discretepoint, holistic, grammar, comprehension, behaviorist, cognitive, functional, communicative and so forth. Most of these genres flow from one or more theories of language learning-each condemning what does not fit the theory. And, as the popular theories change, so changes the interpretation of "modern" and "old-fashioned."

The language lab can accommodate any general type of exercise, both good and bad. Nevertheless, there are some fundamental principles defining "good" activities which can be applied to all types, regardless of theoretical basis.

Moreover, at many such workshops demonstrating various types of language lab activities, inevitably someone discovers, "But these are the same kinds of exercises and activities we do in class!" That realization signals a fundamental breakthrough in understanding the pedagogy of language labs: Most of the activities that are done in the language lab are of the same type as can be done in class. By extension, what makes good and successful classroom activities also contributes to useful language lab activities, and vice versa.

Is this not an admission that the language lab serves no purpose? No. The language lab brings entirely new dimensions and possibilities to the activities. Some activities now done in class can be better done in the lab.

Since many teachers view language labs as instruments for oral/aural practice, they disregard lab use in honing the other senses and skills. Yet, it is no accident that most successful lab programs are accompanied by a workbook; many teachers who design their own activities arrive at the lab with bundles of photocopied worksheets. In many cases, a visual stimulus is more effective, and much more interesting, than a purely audio one. Having to integrate and process visual information in order to form a response precludes a mechanical approach to performing the exercise. Even where the stimulus is only aural, a single picture can serve to contextualize the entire activity, making it seem real and authentic.

The microphone and tape recorder provided at the student position lead many to think that the only form of production allowed is oral. Yet, many lab activities do not call upon the students to record, or even say, anything. Instead, students fill in blanks, write, or draw something in response to aural stimuli.

Many traditional lab activities mimic conversations, typically of the question-answer variety. It is important, in these exercises, that the question-answer pairs represent realistic interchanges. People do not normally answer in full grammatical sentences, nor do they ask questions when they already know the answer; they do not ask the same ten questions over and over, changing only the pronoun each time. If such a task is absolutely required, then a realistic context in which it might naturally occur must be postulated.

Contextualization is one of the accepted "buzzwords" of language practice. It is accepted wisdom that language is retained longer when it represents "real" events, when it conveys a message. Thus, one often sees lab exercises that 
pay "lip service" to the idea of contextualization. Typically, the exercise begins with a short introduction, setting the context:

"Mr. Jones is puzzled that no one has come into the office today. He is asking his secretary, Miss Smith, about the absences."

Where is Mr. Thomas? Mr. Thomas is sick today.

What follows this set-up is a series of ten identical questions-except for some minor alterations-certainly not a realistic conversational interchange. Besides that, the context has no bearing whatsoever on the task. Students soon learn to ignore completely the little introductions. Thus, no one need really worry about whether they can understand it, or whether it sets up sexual or racial stereotypes, as does the one above. For continuity's sake, the same "characters" may be repeated throughout the book, but they are often two-dimensional, paper figures.

Contrast this with exercises where the context indeed matters: It must be taken into account in order to respond correctly; it provides not just a series of realistic interchanges, but a realistic task for the students, something to engage their minds over the course of the entire exercise. Letting characters become fully developed over the course of an exercise help make them "real."

In attempting to make exercises as realistic and contextualized as possible, some methods go too far. If students have too much to worry about at the same time-context, grammar, and vocabulary-they may not be able to complete the task successfully. They will either ignore some of the finer aspects of the task or become frustrated. The language lab is a tool which students can use to engage in controlled practice. As such, it should be used to simulate reality; it must not be used to ask students to do too many things at once.

\section{Controlling the Lab-Essential Elements}

Completing the car analogy, the theory classes are now completed. The written test is over. Now, it is time now to go out onto the road! The road is a dangerous place; even good drivers have accidents. The best defense is to buckle up confidently, drive carefully, and remain in control by watching out for other drivers.

You and I as teachers may have the ideal language lab setup.We may have the best lab materials at our disposal. We may even truly believe in the utility of the language lab and be keen on integrating the lab into the rest of our teaching. All of this counts for nought when the moment of truth arrives: It is time to take the class to the lab!

Like the keys to defensive driving, the keys to the successful management of a lab session are within reach of most, if not all, teachers: 1) confidence, 2) orientation, 3) trouble-shooting, and 4) control.

Teacher Confidence. As teachers, we must be in control of the lab situation at all times. We must feel confident in our knowledge of how the lab works. To gain such confidence, we should not attempt to learn to use the lab in front of our students. Rather, we should make arrangements prior to our first lab session for a personal orientation. Afterwards, we can "play around" with the lab until we are comfortable with it, or at least, with the features that we are going to use.

Any unease about the machinery, or dislike, on our part is very likely to be communicated to our students, feeding and multiplying their own sense of unease and dislike. In such an atmosphere of unease, mistakes on the students' part are presented as "equipment malfunction." Malicious students will learn to play on our frustration and inexperience by deliberately causing disruptive errors. Few, if any of us in teaching, enjoy the personal loss of face that comes from getting flustered and appearing to lose control of the situation in front of our students.

There are practical considerations as well. If we as teachers are unfamiliar with the functioning of a lab, we will make mistakes and thereby waste students' time with re-tries and dead ends. Furthermore, when a student begins to have trouble with a machine, as teachers unfamiliar with the lab, we cannot offer assistance nor can we determine if it is a student-error, a teachererror, or an actual equipment malfunction. There 
is no substitute for a teacher whose confidence rests on a foundation of knowledge on how the language lab works.

Orientation. During the first few sessions, students are the most nervous. Even if we have prepared them for the lab by explaining its rationale, they probably still do not understand all the functions of the equipment. What is more, they cannot yet be aware if the equipment is not working. Part of the purpose of orientation is to sensitize students to some of the more evident telltale signs of equipment malfunction.

Bear in mind that the lab itself is not a language learning exercise. Students need to learn how the equipment works or they will be wasting their time, will get frustrated when they make mistakes, and the learning curve will go down as their affective filter comes up. As teachers helping students learn how lab equipment works, we should use whatever techniques are available to best explain how to use the equipment: Let's not be above explaining how the lab works in the students' first language. Let's not try to teach the whole lab in one sitting; it is too complicated and no one will remember. Let's introduce features one at a time, as they are needed. (This, of course, will have an effect on the planning of your first few lab sessions.)

Students need to know (and therefore we as teachers need to know):

How to adjust headsets comfortably

How to adjust the microphone distance and volume control so that students can hear themselves

How to use the teacher and student volume controls

The use of master track and student track volume controls is crucial because often students hear someone else-in addition to the master track voice-on the tape, and assume that there is something wrong with the machine or the tape. By turning the student track volume OFF or pressing Record, they can turn off or erase a previous student's recording. (This does not work in every lab, but teachers will know this because they will have tried it in their own lab.)
Students need to be completely familiar with a function before they are called upon to use it. Many of the required procedures are new even to those familiar with tape recorders. Hence, students may need to be individually shown. After explaining the function, it is best to launch into a fairly lengthy "practice" activity, during which time you can circulate and personally help those having trouble.

For nearly all activities, students will need to know how to put their individual cassette machines into the Play mode. As teachers we should be careful not to tell students to press the "Play" button if the button actually reads "Listen," or some other phrase. If Play does not resume automatically after Speak-to-Group or Intercom, then students should be reminded verbally to press the Play button:

\section{[Intercom On]}

"Are you having a problem?

Yes?, Okay the answer is ...

Remember to Press Play"

\section{[Intercom Off]}

Failure to remind students will inevitably find some of them leaning on the Teacher Call button, telling the teacher that the equipment is not working. Of course, some students are happy simply sitting out the rest of the activity without saying a word.

For concentrated, individual work on listening activities, such as songs with cloze worksheets, students need to know how to listen again to a word or phrase. This involves Stopping the tape, Rewinding it, then putting the tape into Play again. In many labs, the Rewind function is very fast, and students easily get lost. If there is a Recap function, we should show students how to use it. But we must remember that the Recap function may not work properly on tapes containing normal speed conversation or a musical background. This is because some labs Recap to the previous pause or sentence in a program. This detail is something we as teachers using the lab check out for ourselves beforehand.

It is often better to start off with an individual 
listening activity which only requires students to manipulate Stop and Play. A listening activity with broad-based comprehension questions or a task such as "Write down the five main points discussed" might be appropriate for this beginning level of machine operation.

The Tape Counter should be one of the first things to which we introduce our students. They should be shown how to Reset the Counter at the beginning of each activity, and how to use it to note down the location of things in the program that they wish to review. They should also learn to note down the counter value at the end of the program. Verbal reminders are helpful:

(on Teacher Control)

[Speak to Group]

"Please reset your tape counters to zero."

"As you listen through the first time, jot down the counter number for anything you find interesting."

[Play Master Program/Record on Student Machines]

\section{[Stop Master Program]}

[Speak to Group]

"This is the end of the program. Please write down the tape counter number. Do not go past this number as you do your individual work."

(continue...)

Though many Tape Counters are not truly accurate across different machines, even the worst will give some global indication of location. Teachers should, therefore, make sure they also have noted the counter numbers of key parts of the program. Otherwise, how will they respond to questions like: "What does he mean when he says ... at counter number 155?"

A later skill that students can be introduced to is searching for something on the tape. The student may have already answered the first five comprehension questions as the programme was initially being recorded. The tape is now back at the beginning and the student wants to move forward to the pertinent section for question six. The counter number will not be available for everything, but the student has a general notion of the contents of the section. Searching involves a series of Fast Forward, Stop, and Play sequences. Students must get a feel for how fast the Fast Forward actually moves. Of course, they should know not to go past the ending counter number.

Having students record their own voices can be a complicated endeavor and is definitely something not to be attempted during the first session. In the best of situations, teachers can control the entire operation from the console. In many labs, however, even when under teacher control, students need to activate some button or switch when they wish to record their own voice. Had the students' microphones been improperly adjusted, or been malfunctioning, it is only at this point that it will really become obvious.

The difficulty continues when it is time for playback. If students leave their machines in Record, they will continue to hear the recorded master track, but will be erasing what they themselves recorded earlier. Complaints such as "Teacher, I can't hear" will be issued. But the student's Play/Record switch or buttons may not be the cause.

It could also be the Student Volume. It could also have been microphone adjustment or malfunction during the recording phase (which it would now be too late to correct.)

The first recording activity should probably be something where the whole class can listen back in lock-step fashion. Take, for example, a choral activity where some responding voices are recorded on the master tape. Students will not feel inhibited to join right in, and they will even speak up to be heard over the other voices. On playback, (depending upon the lab equipment being used) the teacher can instruct them to turn the Master Volume off, and they will hear only themselves.

Auto-correction, or Recording/Listening/Rewinding/Re-Recording/Re-Rewinding/Re-Listening, is the operation around which the full function Listening-Speaking-Recording lab was designed. Nevertheless, it is one of the least used functions. It is really only effective in feedbackoriented activities such as pronunication practice. Students must have been previously exposed to 
aural discrimination exercises, so that they can hear the difference between the model and their own performance.

The main factor, however, is that this operation can be difficult for students to manage. It is some time before the rapid succession of control buttons is automatized to the point that students can begin to concentrate on the material rather than on the equipment.

This is not to discount the utility of this type of practice, rather it is to suggest that preparation is required. Over the course of a few sessions, some practice exercises need to be done, while the teacher circulates and shows students individually.

Many of the lab exercises on the market assume that students have mastered the technique; indeed, teachers may think that is what their students are doing, but most have not and are not.

Troubleshooting. As teachers, we may ask why we need to learn some rudimentary troubleshooting. Is that not what the lab operator or technician is for? Yes and No. Simple problems can easily be identified and corrected; they need not unduly disrupt the session. In fact, students may not even know something was wrong. Also, as teachers we need to be able to separate bonafide equipment failures from our own or our students' incorrect actions. Calling the technician for every problem leads to a situation similar to that of the boy who cried wolf too often. The technician's response will become slower and slower.

One of the most common problem areas is with headsets. How to identify headsets that do not work? Some students will sit patiently and not complain even though the acoustic environment in their headset is downright awful. There may be a loud hum, a buzzing sound, static, crosstalk from other students, a local radio station, or no sound at all. Many students will sit quietly and smile through the ordeal.

At the beginning of each session, as the first program is being broadcast, we should quickly monitor each student position. At this time, in most labs, teachers are hearing the sound as the student is hearing it. (Verify this!) If the complaint is low volume, go into Intercom with the student and suggest an increase in volume. If the answer is, "It's up all the way," then there could be a problem. Once possible problem sites are identified, leave the console and briefly listen at the student positions in question. Before moving the student, try unplugging and replugging the headphone into the headphone jack (depending on equipment; some labs do not allow for this). Try moving the microphone boom. Often a loose connection in the microphone circuit can cause sound problems, sometimes for the whole lab! Try another headset. As a last resort, move the student. All the while, the rest of the students are listening to the broadcast.

Even the best headsets become uncomfortable after a few minutes. We should not be afraid to invite students to take them off from time to time. Explanations to the entire class can be made out loud. A thirty-second rest period without headsets is recommended between activities.

Once the entire class is settled into the lab, hopefully there will be at least a few extra positions open. Make it a habit to record activities on these free student machines. In this way, if a student's machine is seen to malfunction during the recording phase of an activity, the student can be quickly moved to another location without disrupting the class. An even more disruptive situation arises when the student notices, at the playback phase, that the machine did not record anything. Rather than having to "sit that one out," the student can be placed at a new position. The most that might be lost is the recording of the student's own voice.

Our students can be sensitized to some of the danger signals of malfunctioning equipment and, thus, enlisted as helpers in troubleshooting operations. For example, while telling students about the Tape Counter, we should remind them that the Counter should be moving as the master program is being recorded from the console. If the counter on a machine does not move, the student should know to signal this fact immediately so that corrective action can be taken. 
Control. Teachers can remain "in control" by avoiding problems, that is, by not letting them happen in the first place.

Each activity should be recorded from the beginning of the tape. Resist the temptation to record several activities in series. It may seem like a good idea to let some students go back and finish an earlier activity, but it may mean they will not catch up with the current activity. Or worse, they will get lost on the tape.

Getting lost on their tape is one of the most frequent problems that students have. They may Fast Forward instead of Rewind, for example. We are guaranteed to have this problem if we do not make it a hard and fast policy to ALWAYS rewind student tapes to the beginning before releasing control to the students. If the lab console allows, we should even put students machines into Play mode just before releasing control.

Getting lost on the tape also happens to us as teachers. We should make sure that our tapes are cued up in advance to the appropriate selection. It is very frustrating for the students to watch uselessly as we "hunt and peck" our way through the master tape. On some labs, there is no way to prevent students from hearing the whole affair. It can become very difficult for us as teachers to maintain our cool while 30 eyes watch.

An added benefit of conducting a lab session as a series of different, short activities is that we can effectively practice "damage control." If an activity does not work, or if half the class is lost at the end of their tapes, we always have the option of taking control, rewinding all the tapes back to the beginning and starting something else, with little time lost.

When recording from the microphone, it is useful to add a final sentence to the recording:

"This is the end of the listening activity. Please rewind the tape and review your work until the class is finished. Do not go any farther."

This-in addition to their noting the Tape Counter number-will help prevent the students of Intermediate Spanish, for example, from continuing with the remains of the Beginning
Spanish drill left on the student tape from the previous class (or worse).

As teachers, many of us misunderstand the proper function of the monitoring capability of the lab. We have been told by the salesman that this allows us to listen for student mistakes and to interrupt and correct students whenever they make errors. How many of us interrupt our students in class every time they make a mistake? Interrupting students disturbs their train-ofthought and intimidates them. It is a last resort and should be reserved for situations where the student is truly lost, obviously missing the whole point of the exercise. Students should not be interrupted when they occasionally use an incorrect verb ending.

As teachers, we should listen for representative errors, which can be brought to the attention of the entire class once the activity is completed. Private notes may be made on the particular problems of certain students. These can be mentioned to them privately later. Observations made while monitoring can serve as a guide to possible future lab activities.

Monitoring the class also allows us to have a general idea of how far in an activity students have progressed. Once the exercise is under way, and every position has been briefly monitored to determine if all is working properly, getting up from the console and walking around the class, looking over students' shoulders, is also highly recommended.

The need to keep up a lively pace has been mentioned earlier, but deserves to be repeated. We need to have a good picture of where in the task everyone is; we must be ready to cut it off at the appropriate time. Students seem to get very anxious when they are finished with an exercise. Sitting alone and bored in their carrels often leads them into mischief: They make noises and disturb others or they begin etching graffiti on the machines or carrels.

Follow up. The time goes by quickly in a wellorchestrated lab session. Both the teacher and the students have been working quite intensely. Rather than feeling that the hour is dragging on, most are likely to find the time too short. 
Once the session has been completed, everyone deserves a short break. Does the lab session end at this point?

No. The material practiced in the lab must be gone over in class. Students must have a chance to finish worksheets and other tasks that were not completed. Teachers have other exercises waiting which will make use of and build on what was done in the lab. It may take several classes before all activities flowing from the lab session have been accomplished. After the follow-up work has been completed, the next lab session must be prepared for with new activities.

After a few successful lab sessions, even the most nervous, skeptical teachers will begin to feel confident and more able to manage and control the lab experience. The first time real disaster strikes-a massive equipment malfunction or a major blunder-they will "sail through it," with only the slightest upset and inconvenience to themselves and their classes.

Teachers who have never accepted language laboratories as "failed technology", or teachers who have abandoned the idea of labs as dinosaurs are "primed" for discovering new and interesting lab activities for their students. As their confidence in using the lab grows, such teachers will engage in maximum exploitation of what the language lab can do to help teachers teach and students learn languages. Together, teachers and students can find their language home in the language laboratory, a specific, special, and remarkable teaching and learning tool for 1989 and beyond.

\section{Contributor Profile}

Roger Kenner directed the Learning Laboratories of Concordia University (Montreal) since 1979 where, over the years, he gained insight into the day-to-day problems faced by teachers and students. At the same time, he also used language labs extensively in his own teaching of EFL at the French-language collegiate level. In 1981, he organized an international colloquium on the re-birth of the language laboratory, held in Montreal. His areas of interest touch all aspects of mediated instruction and, of late, his primary focus has been in the area of computerassisted language learning (CALL). He was elected chair of TESOL's (Teachers of English to Speakers of Other Languages) CALL Interest Section in 1984 and served until 1986. He is currently coordinator of research \& development for the Audio-Visual Department, of which the Learning Labs remain a part. 
JETT Fact Finder: Manufacturers of Language Lab Systems:

The following is a list of some of the major manufacturers with which I am familiar. It should not be taken as a complete, definitive list of manufacturers:

\section{SONY}

Sony Learning Systems

411 Gordon Baker Road

Willowdale, Ontario, M2H-2S6, CANADA (See Ad this issue for U.S. address)

\section{TANDBERG}

1 Labriola Court

P. O. Box 58

Armonk, New York, 10504, USA

\section{REVOX}

Revox ELA AG

Division Exportation

Althardstrasse $146 \mathrm{CH} 8105$

Regensdorf - Zürich, Switzerland

ASC

ASC Electronic

Seibelstrasse 4

D-8759 Hosbach

German Federal Republic

WICOM

Educational Electronics Corp.

P. O. Box 339

Inglewood, CA, 90306-0339, USA

\section{P/H ELECTRONICS}

117 East Helena Street

Dayton, Ohio, 45404, USA

JETT Fact Finder: Conferences/Books/Articles on Language Labs \& Lab Materials

Classic Works:

The language laboratory and modern language teaching by Edward Stack (London: Oxford University Press, 1971).

Language laboratory learning: New direction edited by Louis Chatagnier and Gilbert Taggart (Montreal: Aquila, 1971).
The language laboratory and language learning by Julian Dakin (London: Longman, 1973).

More Recent Works:

Language laboratory management by Ann Hayes (London: The British Council, 1980).

Proceedings of the Concordia Colloquium on Language Labs edited by Roger Kenner (Montreal: SPEAQ Journal, 1981).

Bring the lab back to life by Philip Ely (Oxford: Pergamon Press, 1983).

The communicative teaching of English: Principles and an exercise typology edited by Christopher Candlin (London: Longman, 1978).

Planning and using language learning centers edited by Jerry Larson (Provo, Utah: CALICO, 1986).

Task-Based activities: A communicative approach to language laboratory use by LeeAnn Stone (IALL Publication sponsored by Tandberg Educational, Inc., 1988).

\section{Conferences}

International Association for Learning Laboratories 1989 Conference: IALL '89: Designing, Managing and Using the Language Learning Center of the 90's in Cambridge, MA at the Massachusetts Institute of Technology, July 5-8, 1989.

JETT Fact Finder: Sources for some interesting lab exercises:

It would be fruitless to try listing all the available lab materials. Each new method usually comes with accompanying exercises for the lab. Indeed, many things never conceived for language labs can be adapted quite successfully.

The short list below, therefore, contains a few examples to look at for inspiration:

Para Empezar: Curso comunicativo de español para extranjeros by Ernesto Peris, et al. 
(Madrid: Edi-6, 1983). [An example of very good sound effects, colourful graphics, and the need to take the pictures and the situation into account in order to respond correctly. Fast-paced and interesting.]

Alles Gute by Jeanine Briggs (New York: Random House, 1986). [Though not as glossy as the above, there is a clear need to consider context in order to answer properly.]

Lernziel Deutsch by Wolfgang Hieber (Munich: Max Heuber Verlag, 1987). [Though the official "lab" exercises are skimpy, the so-called "inclass" material can be easily adapted for lab use. It is exemplary in that the characters in the book develop real, and interesting personalities over the course of the book.]

Cartes sur table by Rene Richterich and Brigitte Suter (Paris: Hachette, 1981). [A good, communicative method for French, though some training is required to use it effectively.]

Listening in \& speaking out by Gary James, et al. (New York: Longman, 1980). [Good listening and cloze practice based on real conversations-a great confidence builder for ESL/EFL students.]

Jazz Chants by Carolyn Graham (New York: Oxford University Press, 1978). [Excellent pronunciation and stress practice for ESL/EFL.
Because the sound of other students responding in chorus is recorded on the tape, learners can be "tricked" into speaking out clearly. On playback, with the master track turned off, they hear only themselves.]

Improving Aural Comprehension by Joan Morley (Ann Arbor, University of Michigan Press, 1975). [A huge compendium of listening tasks, accompanied by graphic worksheets the information on which the students must integrate with the spoken text in order to perform properly. It is accompanied by a teachers manual containing the tape script. Most teachers would want to use the microphone rather than use the tape set, which is rather monotone and slow. All of Joan Morley's other materials are equally exemplary.]

Side by Side by Stephen Molinksy and Bill Bliss (New Jersey: Prentice-Hall, 1980). [Though not designed as a lab method, each page contains pictures of mini-situations around which the teacher can easily construct contextualized and communicative lab activities where an understanding of the meaning of the words is essential to responding correctly. Teachers of other languages could easily adapt some of the material in the book.] There is a new edition of Side by Side; the accompanying tape program will be available in Fall of 1989 according to the publisher. 